\title{
Efficient eigenvalue numerical solutions for time dependent linear systems
}

\author{
R. C. Callarotti ${ }^{1} \&$ E. J. Paez ${ }^{2}$ \\ ${ }^{1}$ Universidad del Turabo and Puerto Rico Energy Center, \\ Gurabo, Puerto Rico \\ ${ }^{2}$ Fundacion Instituto de Ingenieria, Caracas, Venezuela
}

\begin{abstract}
We discuss the new application of an efficient numerical method for the calculation of the response of linear multidimensional systems: incompressible fluid flow, heat transfer, electromagnetic problems, and electrochemical systems. The method avoids finite difference time iterations that can diverge for large $(\Delta t)$ intervals. The method determines the poles and zeros for the different systems allowing the direct calculation of the time response of the different systems from trivial evaluation of inverse Laplace transforms. The new application is concerned with finding the temperature distribution inside a cylindrical extra heavy oil reservoir (API $\sim 1$ ) excited by microwave $(5 \mathrm{GHz})$ power. The power is applied at the surface of the earth, transmitted via a circular waveguide operating in the $\mathrm{TE}_{01}$ mode (length 1000 meters), inserted at the center of the reservoir. Our numerical procedure is based on: (i) spatially discretizing the system, (ii) deriving an equivalent circuit for each volume element, (iii) applying a time Laplace transformation and obtaining an admittance matrix, (iv) writing the expressions for the Laplace transforms of the desired variables according to Cramer's determinant rule, (v) interpreting the determinants as generalized eigenvalue problems, (vi) obtaining the proper eigenvalues of the system (poles and zeros), and (vii) finding the time-dependent solutions by 'trivial' inverse Laplace transformations.

In this paper we compare this solution with standard finite difference solutions. We discuss the advantages derived from the application of our proper eigenvalue approach which provides an analytical solution for the calculation of reservoir heating at ANY desired time. From a control theory point of view this
\end{abstract}


approach is very useful for evaluating oil reservoir response to thermal excitations

Keywords: eigenvalues, numerical procedures, heat conduction, microwave petroleum excitation, heavy oil production.

\section{Introduction}

The present paper is concerned with the modeling of the thermal stimulation of an heavy (or extra-heavy) oil reservoir, through the application of $5 \mathrm{GHz}$ microwaves generated at the surface and transmitted to the reservoir via a circular metallic waveguide (either coil tubing or treaded tubing sections). Thermal stimulation of heavy oil has been used for decades, mostly by the intermittent injection of steam into the reservoirs (Prats [1]), while electromagnetic stimulation has been applied in very few instances (Callarotti [2]). Since about half of the total world petroleum reserves are heavy and extra heavy oil (mostly in Venezuela and in Canada), the thermal stimulation of these reservoirs via electrical energy should be examined. In order to determine the feasibility of electro-magnetical down-hole heating (with the corresponding increase in temperature and reduction in oil viscosity) we have analyzed the structure shown in Figure 1.

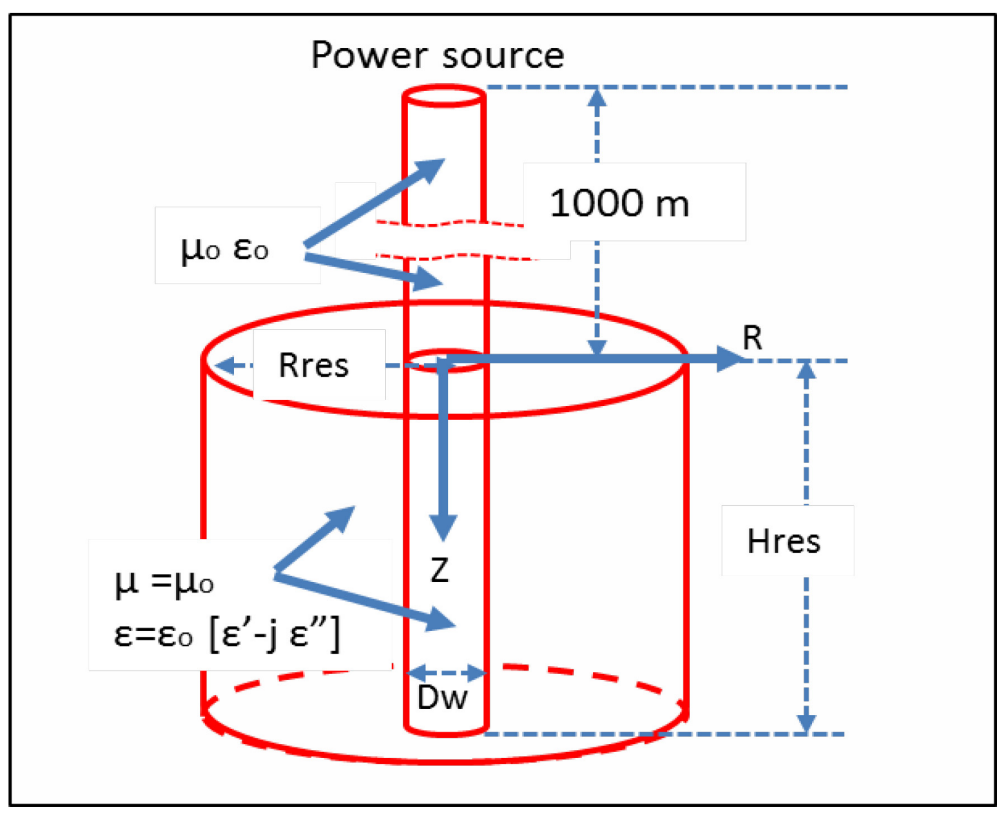

Figure 1: Geometry of the system considered.

The reservoir is modeled as a cylinder of length Hres $=20 \mathrm{~m}$ and outer radius Res $=21.7 \mathrm{~m}$. The well is also a cylinder with a radius $\mathrm{Rw}=0.0762$ meters - 
(3 inches). We chose this cylindrical geometry with axial symmetry so that we can solve numerically the heat transfer equations in two dimensional $r, z$ cylindrical coordinates, with the corresponding reduction in matrix sizes from the three dimensional formulation.

The heat transfer equation that defines the temperature in the well and in the reservoir T(r, z), is (Callarotti [3]):

$$
\begin{aligned}
& \mathrm{K} \vec{\nabla}^{2} \mathrm{~T}(\mathrm{r}, \mathrm{z}, \mathrm{t})=\rho \mathrm{C}_{\mathrm{P}} \frac{\partial \mathrm{T}(\mathrm{r}, \mathrm{z}, \mathrm{t})}{\partial \mathrm{t}}-\mathrm{P}_{\mathrm{PUV}}(\mathrm{r}, \mathrm{z}, \mathrm{t}) \\
& \mathrm{K} \vec{\nabla} \cdot \vec{\nabla} \mathrm{T}(\mathrm{r}, \mathrm{z}, \mathrm{t})=\rho \mathrm{C}_{\mathrm{P}} \frac{\partial \mathrm{T}(\mathrm{r}, \mathrm{z}, \mathrm{t})}{\partial \mathrm{t}}-\mathrm{P}_{\mathrm{PUV}}(\mathrm{r}, \mathrm{z}, \mathrm{t})
\end{aligned}
$$

where the oil reservoir characteristics are: the thermal diffusivity, $\mathrm{K}$ the thermal conductivity $\left(1.5\right.$ joules $/\left(\mathrm{m} \mathrm{sec}^{\circ} \mathrm{K}\right), \rho$ the density $\left(1.0\left(\mathrm{Kg} / \mathrm{m}^{3}\right), \mathrm{C}_{\mathrm{P}}\right.$ the specific heat at constant pressure $\left(2 \mathrm{Kjoule} /\left(\mathrm{Kg}^{\circ} \mathrm{K}\right)\right)$, and $\mathrm{P}_{\mathrm{PUV}}\left(\right.$ watts $\left./ \mathrm{m}^{3}\right)$ is the applied electrical power per unit volume in the well. We discretize in space as shown in Figure 2.

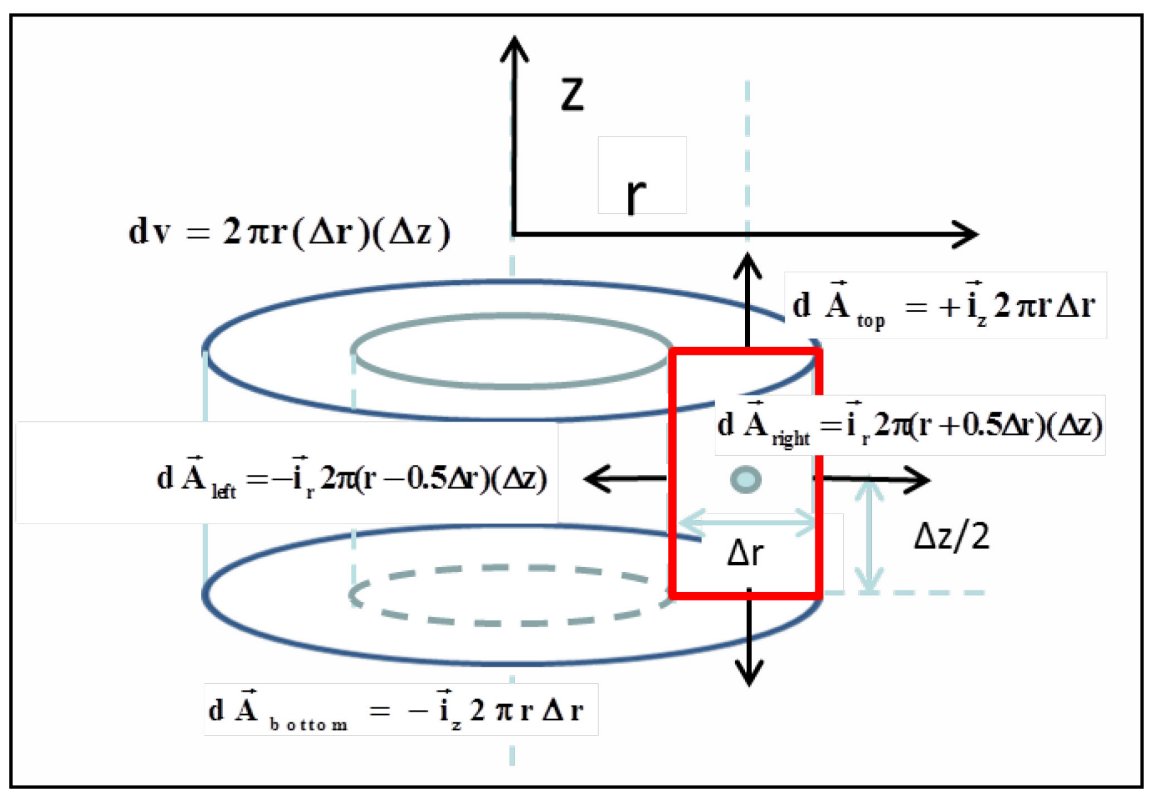

Figure 2: Discretization in space for the cylindrical reservoir and well.

In section 2 we discuss the electromagnetic waves in the well above the reservoir, and those inside the well and into the reservoir. In section 3 we discuss the equivalent circuit that represents heat transfer in each volume element. In section 4 we solve for the temperature in the system by means of our proper eigenvalue model. Finally we present our conclusions. 


\section{Electromagnetic propagation}

As shown in Figure 1, the surface power unit is connected to the reservoir by means of a circular wave guide (diameter 6 inches $-0.1524 \mathrm{~m}$ ) with metallic steel walls. This guide is excited in the TE01 mode (at $5 \mathrm{GHz}$ ) since this is the only mode in circular waveguides whose attenuation (due to losses in the metallic walls) will always decrease as the frequency is increased (Collin [4]). The attenuation for this section which is assumed filled with air (surface to top of the reservoir) is given by:

$$
\alpha_{0,1}^{\mathrm{TE}}\left(\sigma_{\mathrm{m}}\right)=\left\{\frac{\mathrm{R}_{\mathrm{m}}}{\mathrm{aZ}}\right\}\left\{\frac{\frac{\omega_{\mathrm{c}, 0,1}^{2}}{\omega^{2}}}{\sqrt{\left(1-\frac{\omega_{\mathrm{c}, 0,1}^{2}}{\omega^{2}}\right)}}\right\}=\left\{\frac{\mathrm{R}_{\mathrm{m}}}{\mathrm{aZ}}\right\}\left\{\frac{\frac{(3.83)^{2}}{\mathrm{a}^{2} \omega^{2} \mu_{0} \varepsilon_{0}}}{\sqrt{\left(1-\frac{(3.83)^{2}}{\mathrm{a}^{2} \omega^{2} \mu_{0} \varepsilon_{0}}\right)}}\right\}
$$

where $R_{m}, Z_{o}, \sigma_{m}, \mu_{0}$ and $\varepsilon_{0}$ are given by:

$$
\begin{aligned}
& \mathbf{R}_{\mathrm{m}}=\sqrt{\omega \mu_{0} / 2 \sigma_{\mathrm{m}}} \quad \mathrm{Z}_{0}=\sqrt{\mu_{0} / \varepsilon_{0}} \quad \sigma_{\mathrm{m}}=9.6 \times 10^{6} \quad \Omega^{-1} \mathrm{~m}^{-1} \\
& \mu_{0}=4 \pi \times 10^{-7} \text { henry / meter } \quad \varepsilon_{0}=8.854 \times 10^{-12} \text { farads / meter }
\end{aligned}
$$

where we used the conductivity of steel.

The attenuation of the magnetic and electric fields is given by:

$$
\alpha_{0,1}^{\mathrm{TE}}\left(\sigma_{\text {steel }}\right)=8.1 \times 10^{-4} \mathrm{~m}^{-1} \text { at } \mathrm{f}=5 \mathrm{GHz}
$$

For this value of frequency, a power of $1 \mathrm{Kw}$ applied at the surface is reduced to 197.7 watts at the entrance to the reservoir situated 1000 meters below the source. The power attenuation is twice that of the $\mathrm{E}$ and $\mathrm{H}$ fields, since the power transmitted depends on the product of the field amplitudes. In the reservoir the microwave fields are attenuated both by the losses in the metallic walls as well as by losses due to the imaginary component of the permittivity. In the present case of heavy oil we have considered (Erdogan [5], Joshi and Pollard [6] and Westphal [7]) the following permittivity values:

$$
\begin{array}{lll}
\varepsilon^{\prime}=2.3 & \varepsilon^{\prime \prime}=0.010 & \varepsilon^{\prime}>>\varepsilon^{\prime \prime} \\
\varepsilon^{\prime}=2.3 & \varepsilon^{\prime \prime}=0.005 & \varepsilon^{\prime}>>\varepsilon^{\prime \prime} \\
\varepsilon^{\prime}=2.3 & \varepsilon^{\prime \prime}=0.001 & \varepsilon^{\prime}>>\varepsilon^{\prime \prime}
\end{array}
$$

For this case where $\varepsilon^{\prime}>>\varepsilon ”$, the attenuation for the $\mathrm{E}$ and $\mathrm{H}$ fields is given by:

$$
\alpha_{\text {oil }}=\frac{\omega^{2} \mu_{0} \varepsilon_{0} \varepsilon^{\prime \prime}}{\sqrt{\left(\omega^{2} \mu_{0} \varepsilon_{0} \varepsilon^{\prime}-\frac{(3.83)^{2}}{a^{2}}\right)}}
$$


The power attenuation will be the double of the value given in (7). Since the attenuation due to the oil is much larger than the attenuation due to the walls, the power dissipated in the pipe inside the reservoir will vary as:

$$
\begin{aligned}
& P(z)=P o \exp \left(-2 \alpha_{\text {oil }} z\right)=197.7 \exp (-0.728 \mathrm{z}) \text { watts } \quad \varepsilon "=0.01 \\
& P(z)=P o \exp \left(-2 \alpha_{\text {oil }} z\right)=197.7 \exp (-0.364 \mathrm{z}) \text { watts } \quad \varepsilon "=0.005 \\
& P(z)=P o \exp \left(-2 \alpha_{\text {oil }} z\right)=197.7 \exp (-0.0728 \mathrm{z}) \text { watts } \varepsilon "=0.001
\end{aligned}
$$

With these $\mathrm{P}(\mathrm{z})$ dependences, we can now determine the temperature distribution in the reservoir.

\section{Heat transfer equivalent circuit}

We integrate Equation (1) over one element of volume in the reservoir:

$$
\int_{\text {volume }}[\vec{\nabla} \cdot \vec{\nabla} \mathbf{T}(\mathbf{r}, \mathbf{z}, \mathbf{t})] \mathbf{d v}=\int_{\text {volume }}\left[\frac{1}{\kappa} \frac{\partial \mathrm{T}(\mathbf{r}, \mathbf{z}, \mathbf{t})}{\partial \mathrm{t}}-\frac{\mathbf{P}_{\mathrm{PUV}}(\mathbf{r}, \mathbf{z}, \mathbf{t})}{\mathrm{K}}\right] \mathbf{d v}
$$

We then apply Gauss theorem converting the volume integrals of the divergence of a vector to the surface integral of that vector:

$$
\int_{\text {surfaceA }} \vec{\nabla} \mathbf{T}(\mathbf{r}, \mathbf{z}, \mathbf{t}) \cdot \mathbf{d} \overrightarrow{\mathbf{A}}=\int_{\text {volume }}\left[\frac{1}{\kappa} \frac{\partial \mathbf{T}(\mathbf{r}, \mathbf{z}, \mathbf{t})}{\partial \mathbf{t}}-\frac{\mathbf{P}_{\mathbf{P U V}}(\mathbf{r}, \mathbf{z}, \mathbf{t})}{\mathbf{K}}\right] \mathbf{d v}(10)
$$

And in terms of the Laplace time transform of $\mathrm{T}$ with $\mathrm{T}\left(\mathrm{r}, \mathrm{z}, \mathrm{t}=0^{-}\right)=0$, and of the Laplace transform of a step of Power $(r, z, t)$ we have:

$$
\int_{\text {surfaceA }} \vec{\nabla} \mathbf{T}^{\mathrm{L}}(\mathbf{r}, \mathbf{z}) \cdot \mathbf{d} \overrightarrow{\mathbf{A}}=\int_{\text {volume }}\left[\frac{\mathrm{s}}{\kappa} \mathbf{T}^{\mathrm{L}}(\mathbf{r}, \mathbf{z})-\frac{\mathbf{P}_{\text {PUV }}^{\mathrm{L}}(\mathbf{r}, \mathbf{z})}{s K}\right] \mathbf{d v}
$$

Evaluating the integrals for the geometry element shown in Figure 1, we find:

$$
\begin{aligned}
& -\left[\frac{T^{\mathrm{L}}(\mathbf{r}, \mathbf{z})-\mathrm{T}^{\mathrm{L}}(\mathbf{r}-0.5 \Delta \mathrm{r}, \mathrm{z})}{\Delta \mathbf{r}}\right][2 \pi(\mathbf{r}-0.5 \Delta \mathbf{r}) \Delta \mathrm{z}] \\
& +\left[\frac{T^{\mathrm{L}}(\mathbf{r}+0.5 \Delta \mathrm{r}, \mathrm{z})-\mathrm{T}^{\mathrm{L}}(\mathrm{r}, \mathrm{z})}{\Delta \mathrm{r}}\right][2 \pi(\mathrm{r}+0.5 \Delta \mathrm{r}) \Delta \mathrm{z}] \\
& +\left[\frac{T^{\mathrm{L}}(r, z+0.5 \Delta \mathrm{z})-T^{\mathrm{L}}(\mathrm{r}, \mathrm{z})}{\Delta \mathrm{z}}\right][2 \pi \mathrm{r} \Delta \mathrm{r}]-\left[\frac{\mathrm{T}^{\mathrm{L}}(\mathrm{r}, \mathrm{z})-\mathrm{T}^{\mathrm{L}}(\mathrm{r}, \mathrm{z}-0.5 \Delta \mathrm{z})}{\Delta \mathrm{z}}\right][2 \pi \mathrm{r} \Delta \mathrm{r}] \\
& =2 \pi \mathrm{r} \Delta \mathrm{r} \Delta \mathrm{z}\left[\frac{\mathrm{sT}^{\mathrm{L}}}{\mathrm{K}}-\frac{\mathbf{P}_{\mathrm{PUV}}(\mathrm{r}, \mathrm{z})}{\mathrm{K} \mathrm{s}}\right]
\end{aligned}
$$


Equations represented at each node (ir, iz) by the equivalent circuit shown in Figure 3. The circuit elements joining nodes $0.5 \Delta \mathrm{r}$ and $0.5 \Delta \mathrm{z}$ apart are:

$$
\begin{aligned}
& Y_{r r}=K\left[\frac{2 \pi(\Delta z)\left(r_{n}+0.5 \Delta r\right)}{(\Delta r)}\right] \\
& Y_{r l}=K\left[\frac{2 \pi(\Delta z)\left(r_{n}-0.5 \Delta r\right)}{(\Delta r)}\right] \\
& Y_{z u}=Y_{z d}=K\left[\frac{2 \pi r_{n}(\Delta r)}{(\Delta z)}\right]
\end{aligned}
$$

$$
\begin{gathered}
\text { ITexc }=\left[\rho c_{p} T\left(r, z, t=0^{-}\right)+P_{\text {puv }}^{L}\right] 2 \pi \operatorname{rn}(\Delta r)(\Delta z) \\
C=\rho c_{p} 2 \pi(\Delta r)(\Delta z)(r n)
\end{gathered}
$$

The well and reservoir equivalent circuit is shown in Figure 4 (for a reduced number of nodes).

If the steady state solution is desired the capacitors in the above circuit are omitted. The transient response according to our proper eigenvalue procedure is described next.

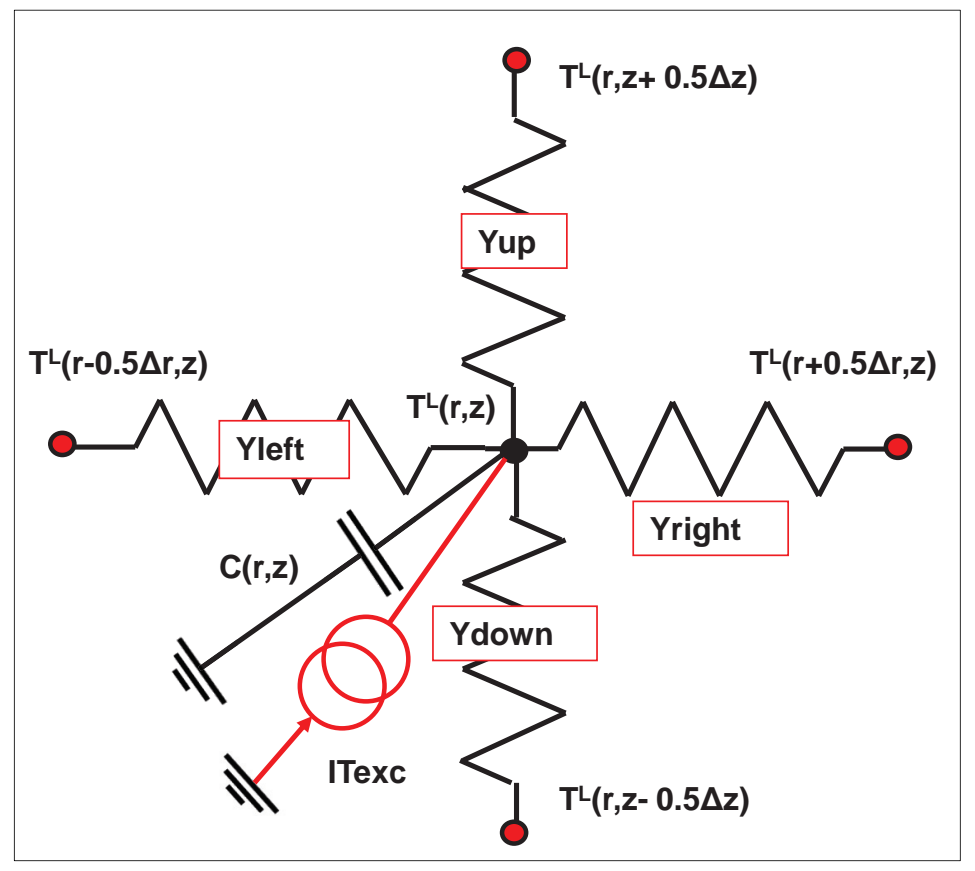

Figure 3: Equivalent circuit for heat transfer in each volume element. 


\section{Transient solution in terms of eigenvalues}

For the $3 \times 3$ node system shown above we can write (dots indicate zeros).

$$
\left[\begin{array}{ccccccccc}
\mathbf{a}_{11}+\mathbf{s c}_{1} & -\mathbf{a}_{12} & \cdot & -\mathbf{a}_{14} & \cdot & \cdot & \cdot & \cdot & \cdot \\
-\mathbf{a}_{21} & \mathbf{a}_{22}+\mathbf{s c}_{2} & -\mathbf{a}_{23} & \cdot & -\mathbf{a}_{25} & \cdot & \cdot & \cdot & \cdot \\
\cdot & -\mathbf{a}_{32} & \mathbf{a}_{33}+\mathbf{s c}_{3} & -\mathbf{a}_{34} & \cdot & -\mathbf{a}_{36} & \cdot & \cdot & \cdot \\
-\mathbf{a}_{41} & \cdot & -\mathbf{a}_{43} & \mathbf{a}_{44}+\mathbf{s c}_{4} & -\mathbf{a}_{45} & \cdot & -\mathbf{a}_{47} & \cdot & \cdot \\
\cdot & -\mathbf{a}_{52} & \cdot & -\mathbf{a}_{54} & \mathbf{a}_{55}+\mathbf{s c}_{5} & -\mathbf{a}_{56} & \cdot & -\mathbf{a}_{58} & \cdot \\
\cdot & \cdot & -\mathbf{a}_{63} & \cdot & -\mathbf{a}_{65} & \mathbf{a}_{66}+\mathbf{s c}_{6} & -\mathbf{a}_{67} & \cdot & -\mathbf{a}_{69} \\
\cdot & \cdot & \cdot & -\mathbf{a}_{74} & \cdot & -\mathbf{a}_{76} & \mathbf{a}_{77}+\mathbf{s c}_{7} & -\mathbf{a}_{78} & \cdot \\
\cdot & \cdot & \cdot & \cdot & -\mathbf{a}_{85} & \cdot & -\mathbf{a}_{87} & \mathbf{a}_{88}+\mathbf{s c}_{8} & -\mathbf{a}_{89} \\
\cdot & \cdot & \cdot & \cdot & \cdot & -\mathbf{a}_{96} & \cdot & -\mathbf{a}_{98} & \mathbf{a}_{99}+\mathbf{s c}_{9}
\end{array}\right]\left[\begin{array}{c}
\mathbf{T}_{1}^{\mathrm{L}} \\
\mathbf{T}_{2}^{\mathrm{L}} \\
\mathbf{T}_{3}^{\mathrm{L}} \\
\mathbf{T}_{4}^{\mathrm{L}} \\
\mathbf{T}_{5}^{\mathrm{L}} \\
\mathbf{T}_{6}^{\mathrm{L}} \\
\mathbf{T}_{7}^{\mathrm{L}} \\
\mathbf{T}_{8}^{\mathrm{L}} \\
\mathbf{T}_{9}^{\mathrm{L}}
\end{array}\right]=\left[\begin{array}{c}
\mathbf{P}_{1}^{\mathrm{L}} \\
\cdot \\
\cdot \\
\mathbf{P}_{4}^{\mathrm{L}} \\
\cdot \\
\cdot \\
\mathbf{P}_{7}^{\mathrm{L}} \\
\cdot \\
\cdot
\end{array}\right]
$$

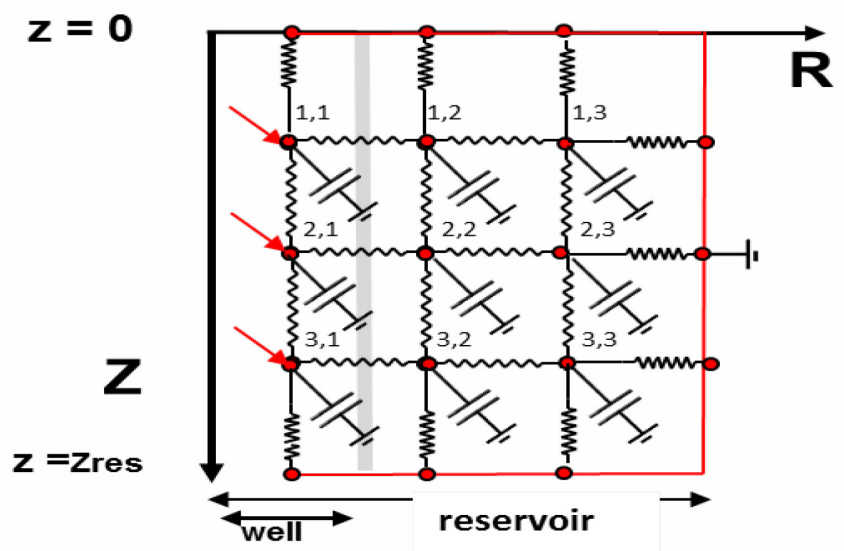

Figure 4: $\quad$ The system equivalent circuit (only $3 \times 3$ nodes are shown).

We now divide each row of the above matrix by $c_{i}$ defining $b_{i j}=a_{i j} / c_{i}$, obtaining:

$$
\left[\begin{array}{ccccccccc}
\mathbf{b}_{11}+\mathbf{s} & -\mathbf{b}_{12} & \cdot & -\mathbf{b}_{14} & \cdot & \cdot & \cdot & \cdot & \cdot \\
-\mathbf{b}_{21} & \mathbf{b}_{22}+\mathbf{s} & -\mathbf{b}_{23} & \cdot & -\mathbf{b}_{25} & \cdot & \cdot & \cdot & \cdot \\
\cdot & -\mathbf{b}_{32} & \mathbf{b}_{33}+\mathbf{s} & -\mathbf{b}_{34} & \cdot & -\mathbf{b}_{36} & \cdot & \cdot & \cdot \\
-\mathbf{b}_{41} & \cdot & -\mathbf{b}_{43} & \mathbf{b}_{44}+\mathbf{s} & -\mathbf{b}_{45} & \cdot & -\mathbf{b}_{47} & \cdot & \cdot \\
\cdot & -\mathbf{b}_{52} & \cdot & -\mathbf{b}_{54} & \mathbf{b}_{55}+\mathbf{s} & -\mathbf{b}_{56} & \cdot & -\mathbf{b}_{58} & \cdot \\
\cdot & \cdot & -\mathbf{b}_{63} & \cdot & -\mathbf{b}_{65} & \mathbf{b}_{66}+\mathbf{s} & -\mathbf{b}_{67} & \cdot & -\mathbf{b}_{69} \\
\cdot & \cdot & \cdot & -\mathbf{b}_{74} & \cdot & -\mathbf{b}_{76} & \mathbf{b}_{77}+\mathbf{s} & -\mathbf{b}_{78} & \cdot \\
\cdot & \cdot & \cdot & \cdot & -\mathbf{b}_{85} & \cdot & -\mathbf{b}_{87} & \mathbf{b}_{88}+\mathbf{s} & -\mathbf{b}_{89} \\
\cdot & \cdot & \cdot & \cdot & \cdot & -\mathbf{b}_{96} & \cdot & -\mathbf{b}_{98} & \mathbf{b}_{99}+\mathbf{s}
\end{array}\right]\left[\begin{array}{c}
\mathbf{T}_{1}^{\mathrm{L}} \\
\mathbf{T}_{2}^{\mathrm{L}} \\
\mathbf{T}_{3}^{\mathrm{L}} \\
\mathbf{T}_{4}^{\mathrm{L}} \\
\mathbf{T}_{5}^{\mathrm{L}} \\
\mathbf{T}_{6}^{\mathrm{L}} \\
\mathbf{T}_{7}^{\mathrm{L}} \\
\mathbf{T}_{8}^{\mathrm{L}} \\
\mathbf{T}_{9}^{\mathrm{L}}
\end{array}\right]=\left[\begin{array}{c}
\mathbf{P}_{1}^{\mathrm{L}} / \mathbf{c}_{1} \\
\cdot \\
\cdot \\
\cdot \\
\cdot \\
\cdot \\
\cdot \\
\cdot \\
\mathbf{P}_{4}^{\mathrm{L}} / \mathbf{C}_{4} \\
\mathbf{P}_{7}^{\mathrm{L}} / \mathbf{c}_{7} \\
\cdot
\end{array}\right]
$$


Let us now consider evaluate the Laplace transform of the temperature at the first node, in accordance to Cramer determinant rule:

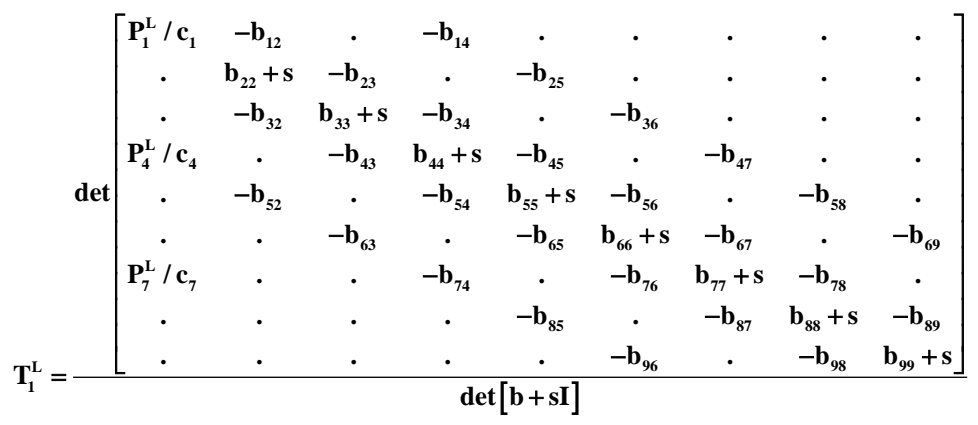

Since all the power is applied as a step in time, we can rewrite the above equation as:

$$
\mathrm{T}_{1}^{\mathrm{L}}=\frac{1}{\mathrm{~s}} \frac{\operatorname{det}[\mathrm{A}]+\mathrm{s}[\mathrm{B}]}{\operatorname{det}[\mathrm{b}+\mathrm{sI}]}
$$

where the matrices $\mathrm{A}$ and $\mathrm{B}$ are:

$$
[\mathbf{A}]=\left[\begin{array}{ccccccccc}
\mathbf{P}_{1} / \mathbf{c}_{1} & -\mathbf{b}_{12} & \cdot & -\mathbf{b}_{14} & \cdot & \cdot & \cdot & \cdot & \cdot \\
\cdot & \mathbf{b}_{22} & -\mathbf{b}_{23} & \cdot & -\mathbf{b}_{25} & \cdot & \cdot & \cdot & \cdot \\
\cdot & -\mathbf{b}_{32} & \mathbf{b}_{33} & -\mathbf{b}_{34} & \cdot & -\mathbf{b}_{36} & \cdot & \cdot & \cdot \\
\mathbf{P}_{4} / \mathbf{c}_{4} & \cdot & -\mathbf{b}_{43} & \mathbf{b}_{44} & -\mathbf{b}_{45} & \cdot & -\mathbf{b}_{47} & \cdot & \cdot \\
\cdot & -\mathbf{b}_{52} & \cdot & -\mathbf{b}_{54} & \mathbf{b}_{55} & -\mathbf{b}_{56} & \cdot & -\mathbf{b}_{58} & \cdot \\
\cdot & \cdot & -\mathbf{b}_{63} & \cdot & -\mathbf{b}_{65} & \mathbf{b}_{66} & -\mathbf{b}_{67} & \cdot & -\mathbf{b}_{69} \\
\mathbf{P}_{7} / \mathbf{c}_{7} & \cdot & \cdot & -\mathbf{b}_{74} & \cdot & -\mathbf{b}_{76} & \mathbf{b}_{77} & -\mathbf{b}_{78} & \cdot \\
\cdot & \cdot & \cdot & \cdot & -\mathbf{b}_{85} & \cdot & -\mathbf{b}_{87} & \mathbf{b}_{88} & -\mathbf{b}_{89} \\
\cdot & \cdot & \cdot & \cdot & \cdot & -\mathbf{b}_{96} & \cdot & -\mathbf{b}_{98} & \mathbf{b}_{99}
\end{array}\right]
$$

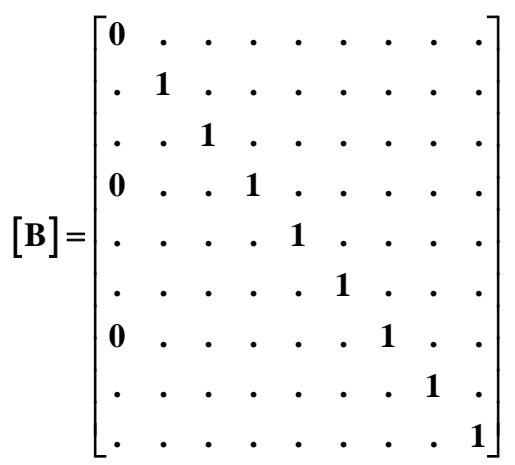


$\operatorname{det}\left[\begin{array}{ccccccccc}\mathbf{P}_{1}^{\mathrm{L}} / \mathbf{c}_{1} & -\mathbf{b}_{12} & \cdot & -\mathbf{b}_{14} & \cdot & \cdot & \cdot & \cdot & \cdot \\ \cdot & \mathbf{b}_{22}+\mathbf{s} & -\mathbf{b}_{23} & \cdot & -\mathbf{b}_{25} & \cdot & \cdot & \cdot & \cdot \\ \cdot & -\mathbf{b}_{32} & \mathbf{b}_{33}+\mathbf{s} & -\mathbf{b}_{34} & \cdot & -\mathbf{b}_{36} & \cdot & \cdot & \cdot \\ \mathbf{P}_{4}^{\mathrm{L}} / \mathbf{c}_{4} & \cdot & -\mathbf{b}_{43} & \mathbf{b}_{44}+\mathbf{s} & -\mathbf{b}_{45} & \cdot & -\mathbf{b}_{47} & \cdot & \cdot \\ \cdot & -\mathbf{b}_{52} & \cdot & -\mathbf{b}_{54} & \mathbf{b}_{55}+\mathbf{s} & -\mathbf{b}_{56} & \cdot & -\mathbf{b}_{58} & \cdot \\ \cdot & \cdot & -\mathbf{b}_{63} & \cdot & -\mathbf{b}_{65} & \mathbf{b}_{66}+\mathbf{s} & -\mathbf{b}_{67} & \cdot & -\mathbf{b}_{69} \\ \mathbf{P}_{7}^{\mathrm{L}} / \mathbf{c}_{7} & \cdot & \cdot & -\mathbf{b}_{74} & \cdot & -\mathbf{b}_{76} & \mathbf{b}_{77}+\mathbf{s} & -\mathbf{b}_{78} & \cdot \\ \cdot & \cdot & \cdot & \cdot & -\mathbf{b}_{85} & \cdot & -\mathbf{b}_{87} & \mathbf{b}_{88}+\mathbf{s} & -\mathbf{b}_{89} \\ \cdot & \cdot & \cdot & \cdot & \cdot & -\mathbf{b}_{96} & \cdot & -\mathbf{b}_{98} & \mathbf{b}_{99}+\mathbf{s}\end{array}\right]$

The eigenvalues for the above determinants (the zeros and poles of the system, are obtained from the FORTRAN programs DEVLRG and DGVLRG available in the IMSL library. These programs are based on the work of Moler and Stewart [8] and the work of Kaufman [9]. In terms of the eigenvalues for the numerator and denominator in (22) we obtain the Laplace transform of $\mathrm{T}_{1}$ as given by:

$$
\begin{aligned}
& T_{1}^{L}(s)=\frac{1}{s} \frac{k_{n} \prod_{i=1 t 09}\left(s-z_{i}\right)}{k_{d} \prod_{j=1 t 09}\left(s-p_{j}\right)} \equiv\left(P_{F}\right)\left[\frac{1}{s} \frac{\prod_{i=1 t o 9}\left(s-z_{i}\right)}{\prod_{j=1 t o 9}\left(s-p_{j}\right)}\right] \\
& T_{1}(t) \equiv P_{F} \sum_{k=1}^{9} R_{k} \exp \left(p_{k} t\right) \\
& R_{k}=\left[\frac{\left(s-s_{k}\right) \prod_{i=1 t 09}\left(s-z_{i}\right)}{s \prod_{j=1 t 09}\left(s-p_{j}\right)}\right]_{s=s k}
\end{aligned}
$$

The pre-factor $\mathrm{P}_{\mathrm{F}}$ is determined from the steady state solution for $\mathrm{T}_{1}(\mathrm{t}=\infty)$ as follows:

$$
\begin{aligned}
& T_{1}(t \rightarrow \infty)=\operatorname{Lim}_{s \rightarrow 0}\left(s T_{1}^{L}(s)\right)=\left(P_{F}\right) \operatorname{Lim}_{s \rightarrow 0}\left(s \frac{1}{s} \frac{\prod_{i=1 t 09}\left(s-z_{i}\right)}{\prod_{j=1 t 09}\left(s-P_{j}\right)}\right) \\
& T_{1}(t \rightarrow \infty)=P_{F} \frac{\prod_{i=1 t 09}\left(-z_{i}\right)}{\prod_{j=1 t 09}\left(-p_{j}\right)} \\
& P_{F}=T_{1}^{\text {steady state }} \frac{\prod_{j=1 \text { to9 }}\left(-\mathbf{p}_{j}\right)}{\prod_{i=1 \text { to9 }}\left(-z_{i}\right)}
\end{aligned}
$$

Once the poles and the zeros and the stationary response of the system are known, the transient solution is obtained trivially. Since the ratio of the two determinants is evaluated step by step (for each zero and pole), the ratio of very large determinants can be evaluated as shown initially by Callarotti [10]. Once that the poles for the system are determined, and once the zeros for the chosen measuring point are evaluated according to Equations (22) and (23), the answer 
for ANY value of time is calculated trivially. The system function has been obtained. This is NOT POSSIBLE by numerical iteration.

\section{Transient solution in terms of finite differences iterations}

We find the finite difference solution applying Gauss theorem to equation 9, multiplying by $\mathrm{K}$ and using the "circuit" elements defined in Equations (13) to (16), at any internal point in the reservoir $\left(1<\mathrm{ir}<\mathrm{irm}, 1<\mathrm{iz}<\mathrm{izm}, \mathrm{P}_{\mathrm{PUV}}(\mathrm{ir}, \mathrm{iz})=0\right)$ we will find:

$$
\begin{aligned}
\mathbf{T}(\mathbf{r}, \mathrm{z}, \mathrm{t}+\Delta \mathrm{t}) & =\mathbf{T}(\mathbf{r}, \mathrm{z}, \mathrm{t})-\left[\frac{\Delta \mathrm{t}}{2 \mathrm{C}}\right]\left[\mathrm{T}(\mathrm{r}, \mathrm{z}, \mathrm{t})\left(\mathbf{Y}_{\mathrm{RL}}+\mathbf{Y}_{\mathrm{RR}}+\mathbf{Y}_{\mathrm{ZU}}+\mathbf{Y}_{\mathrm{ZD}}\right)\right] \\
+ & {\left[\frac{\Delta \mathrm{t}}{2 \mathrm{C}}\right]\left[(\mathrm{T}(\mathrm{r}-\Delta \mathrm{r}, \mathrm{z}, \mathrm{t}))\left(\mathbf{Y}_{\mathrm{RL}}\right)+(\mathrm{T}(\mathrm{r}+\Delta \mathrm{r}, \mathrm{z}, \mathrm{t}))\left(\mathbf{Y}_{\mathrm{RR}}\right)\right] } \\
+ & {\left[\frac{\Delta \mathrm{t}}{2 \mathrm{C}}\right]\left[(\mathrm{T}(\mathrm{r}, \mathrm{z}-\Delta \mathrm{z}, \mathrm{t}))\left(\mathbf{Y}_{\mathrm{ZD}}\right)+(\mathrm{T}(\mathrm{r}, \mathrm{z}+\Delta \mathrm{z}, \mathrm{t}))\left(\mathbf{Y}_{\mathrm{ZU}}\right)\right] }
\end{aligned}
$$

At the external boundaries of the reservoir, equation 25 is modified so as to account for the boundary conditions and the fact that power is applied at nodes (ir=1, iz).

\section{Results}

In Figure 5 we show the steady state temperature $T(i r=1, z)$ vs the depth into the reservoir for the three values of $\varepsilon$ " considered. As expected the curve for the lowest $\varepsilon "=0.001$ value shows the smallest initial temperature increase and a more uniform temperature distribution along the well in the reservoir. The temperature

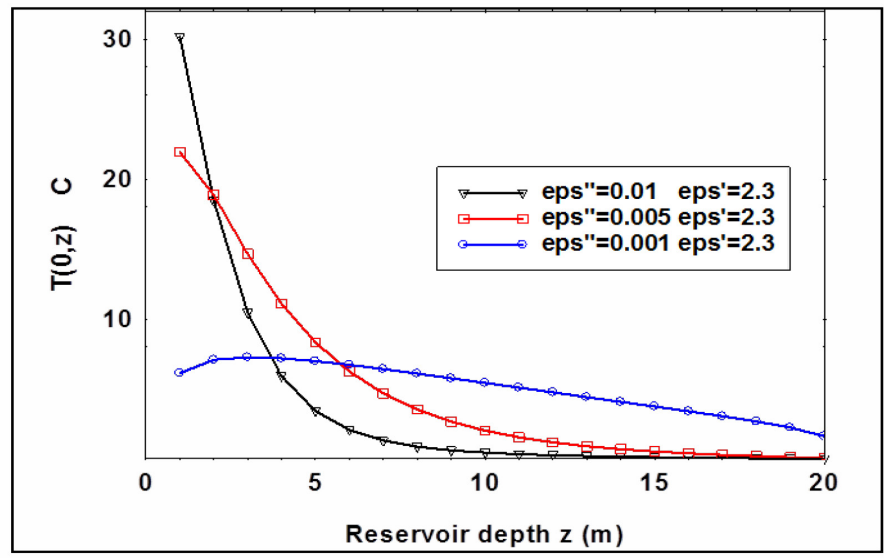

Figure 5: Steady state temperature inside the well (ir=1) as a function of the depth for different values of the imaginary relative permittivity. 
values shown correspond to a surface applied power of $1 \mathrm{Kw}$. As the system considered is linear, as the input power is scaled to different values, the temperatures in the system will scale accordingly. We use an initial temperature of $\mathrm{T}(\mathrm{r}, \mathrm{z})=0 \mathrm{C}$ and if we had used an initial temperature of $\mathrm{T} 0$ degrees $\mathrm{C}$, then $\mathrm{T} 0$ should be added to the temperatures shown.

Figure 6 shows the time dependent temperature at the first point inside the well inside the reservoir ( $\mathrm{ir}=1, \mathrm{iz}=1$ ) as a function of time, as calculated from the proper eigenvalue method and as calculated from the finite difference method. He time response occurs in seconds.

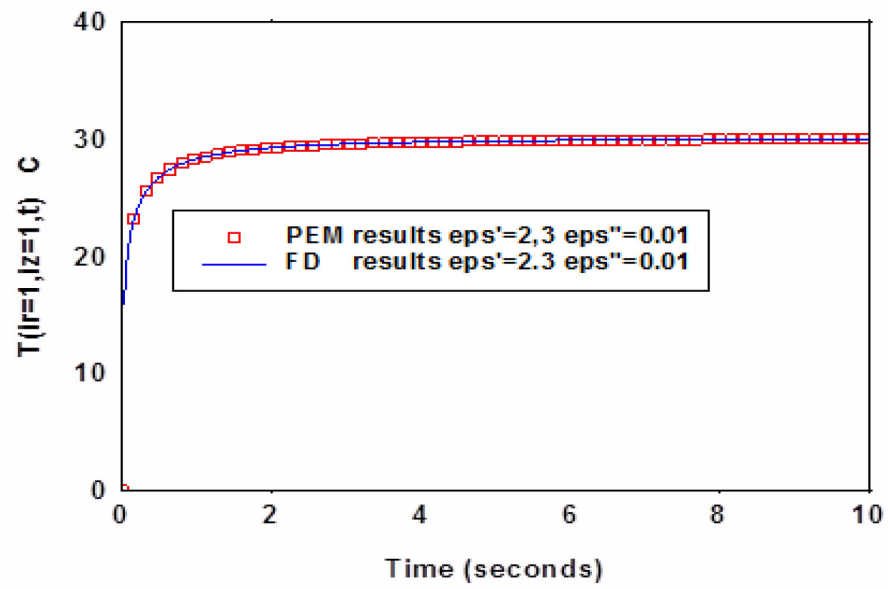

Figure 6: Time dependent temperature at the first node (inside the well inside the reservoir as calculated by our eigenvalue method (PEM) and by the finite difference approach (FD).

\section{Conclusions}

We have determined the response of a reservoir of heavy to extra heavy petroleum under excitation by $5 \mathrm{GHz}$ microwaves. The eigenvalue method used determines the zeros and poles for the system, thus providing an expression for the system response of the system. In this paper we calculated the response for a time step power excitation, but the method can provide the answer for other time function excitations, via simple convolutions. The system type response cannot be obtained via numerical iterations.

\section{References}

[1] Prats M., Thermal Recovery, Doherty Series Vol. 7, The American Institute of Mining Metallurgical and Petroleum Engineers Inc., 1972. Extended version printed as Procesos Termicos de Extraccion de Petroleo, INTEVEP S. A., 1987. 
[2] Callarotti, R. C., Electromagnetic heating of oil, in SPE Handbook of Petroleum Engineering Vol.6; Chapter 12, Lake, L., Ed., Society of Petroleum Engineers: Houston, TX, USA, 2007; Volume 6, pp. 567-609.

[3] Callarotti R. C., "Energy return on energy invested for the production of methane from hydrates by electrical heating and by hot water injection", Open access paper, 2nd World Sustainability Forum, 1-30 November 2012.

[4] Collin R.E., "Foundations for Microwave Engineering", IEEE Press series on electromagnetic wave theory, Wiley Inter-science, New York, 2001.

[5] Erdogan L., "Dielectric Properties of Oil Sands at $2.45 \mathrm{GHz}$ with TE1,0,11 Mode Determined by a Rectangular Cavity Resonator", Journal of Microwave Power and Electromagnetic Energy, pp. 15-2345 (1), 2011.

[6] Joshi K. K. and Pollard R. D., "Sensitivity analysis and experimental investigation of microstrip resonator technique for the in-process moisture/permittivity measurements of petrochemicals and emulsions of crude oil and water", IEEE MTT-S Microwave Symposium Digest, pp. 1624-1637, 11-16, June 2006.

[7] Westphal W. B., MIT Laboratory for Insulation Research, personal communication, 1990.

[8] Moler C. B. and Stewart, G.W. "An algorithm for generalized eigenvalue problems", SIAM J. Numer. Anal., 10, No. 2, 241, 1973.

[9] Kaufman, L.: "The LZ algorithm to solve the generalized eigenvalue problem for complex matrices", ACM Trans. on Math. Software, 1, No. 3, 271, 1975.

[10] Callarotti R. C., "Proper Eigenvalue Solution for the Transient Response of Multidimensional Heat Transfer Systems", Communications in Numerical Methods in Engineering, Vol. 11, 1 p. 715-25, 1995. 